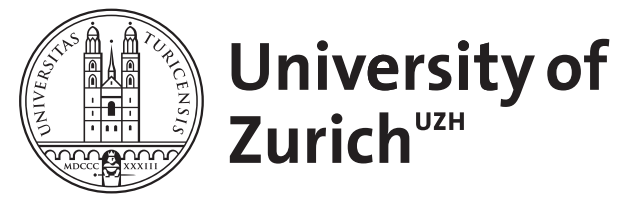

\title{
Helminth-Cestode: Echinococcus granulosus and Echinococcus mutilocularis
}

\author{
Torgerson, P R
}

DOI: https://doi.org/10.1016/B978-0-12-378612-8.00147-5

Posted at the Zurich Open Repository and Archive, University of Zurich ZORA URL: https://doi.org/10.5167/uzh-94133

Book Section

Accepted Version

Originally published at:

Torgerson, P R (2014). Helminth-Cestode: Echinococcus granulosus and Echinococcus mutilocularis. In: Motarjemi, Y. Encyclopedia of Food Safety. Waltham, MA: Elsevier, 63-69.

DOI: https://doi.org/10.1016/B978-0-12-378612-8.00147-5 
147. Echinococcus granulosus and Echinococcus mutilocularis

P. R. Torgerson

Section for Veterinary Epidemiology

Vetsuisse Faculty

University of Zurich

Switzerland 


\section{$\underline{\text { Keywords }}$}

Cystic echinococcosis, alveolar echinococcosis, hydatid disease.

\section{Glossary of terms}

Human cystic echinococcosis.

A disease resulting in a space occupying lesion in any organ, but most commonly in the liver or lungs. The lesion is cystic in nature and cause by the larval stage of Echinococcus granulosus

Human alveolar echinococcosis.

An infiltrative lesion of the liver with metastasises to other organs in the late stage.

Caused by the larval stage of Echinococcus multilocularis. Often fatal if not treated. Hydatid disease.

An alternative name given to cystic echinococcosis. Occasionally it is also used for alveolar echinococcosis.

DALY.

Disability Adjusted Life Year. A metric used to measure the burden of disease in society.

\section{Brief Author Biography}

Studied Veterinary Medicine at Cambridge University, England and subsequently undertook a PhD in Parasitology. After a series of academic appointments in Ireland, Switzerland and the Caribbean, appointed as Professor of Veterinary Epidemiology at Zurich University, Switzerland. Main interests include the epidemiology and control of echinococcosis. 


\section{Characteristics of Echinococcus and life cycle}

Echinococcus spp are cestode parasites belonging to the family Taeniidae. All taeniid parasites have complex life cycles that include a carnivorous definitive host and a second mammalian intermediate host in which the larval or metacestode develops. It is the larval stage that is pathogenic to humans and other mammals. The adult stage is a small tapeworm 2-7 mm in length that inhabits the small intestine of carnivores such as dogs or foxes. Echinococcus granulosus generally infects dogs (figure 1) whilst E. multilocularis the usual definitive host are foxes, but the parasite will also infect dogs (figure 2). Molecular evidence suggests that E. granulosus is really a complex of several species with different intermediate host preferences and variable pathogenicity to man (table 1, figure 1). E. granulosus sheep strain (E. granulosus sensu stricto) is the most important human pathogen. Echinococcus adults characteristically produce taeniid eggs, approximately 40um in diameter. These eggs are morphological indistinguishable from eggs produced by tapeworms of the genus Taenia. The eggs are passed in the faeces of the definitive host and are infective to the intermediate host. The larval stage in intermediate hosts develops as metacestode usually in the visceral organs (see figure 1). Humans are aberrant intermediate hosts and become infected by ingestion of Echinococcus spp. Eggs. When humans are infected with the E. granulosus complex, cystic echinococcosis (CE) develops, which is a space occupying fluid filled cyst. Alveolar echinococcosis (AE) develops when humans are infected with $E$. multilocularis larvae. This results in a more infiltrative lesion, initially in the liver, which can metastasize in the late stage and is usually fatal if untreated. Echinococcosis can be directly transmitted from contact with infected dogs or foxes or indirectly through a variety of ways including contaminated food or water.

Insert Figure $1 \& 2$ and Table 1 about here

\section{Human echinococcosis}

Human echinococcosis occurs following ingestion of eggs and the development of the metacestode in one or more organs. The liver is the most common site for CE followed by the lungs. Other organs are occasionally affected (figures 3 and 4). The disease has been recorded all age groups with the peak age at the time of diagnosis is 30-50 years. Symptomatology depends on: 1) the organ involved, 2) the size and location of the cyst within the invaded organ(s), 3) pressure induced within organ(s), and 4) complications such as rupture and spread of larval tissue with formation of secondary cysts and possible sepsis. Cyst rupture may also lead to anaphylaxis.

Insert Figures 3 and 4 about here 
The primary lesion for $\mathrm{AE}$ is the liver. The slowly growing infiltrative lesion may be present for several years before clinical signs become apparent. These include abdominal pain, jaundice, sometimes fever and anaemia. This advances to severe hepatic dysfunction, and is often associated with portal hypertension. The lesion will continue to grow and eventually metastasize to other organs and usually has a fatal outcome in the absence of treatment. In Europe the peak age of diagnosis is approximately 50-55 years. In other endemic areas such as China this may be lower. However the disease has been recorded in all age groups

\section{Diagnosis}

Ultrasound examination (US), a widely used technique, can confirm the diagnosis of abdominal echinococcosis and indicate if lesions are active. Pulmonary echinococcosis cannot normally be detected by US. Classification systems based on the US appearance of the cyst have been developed for $\mathrm{CE}$ and $\mathrm{AE}$ which may provide important information to the physician managing the case.

Nuclear magnetic resonance (NMR) (figure 3) or computer aided tomography (CAT-scan) (figure 4) can be used to confirm the diagnosis, especially for lung and brain cysts, and to perform a pre-therapeutic assessment of the lesions, for all locations. Unfortunately, in many remote endemic areas such facilities are not available. In this case, serological back-up tests may be required to give additional information regarding the nature of the lesion detected by US.

A large number of serological assays have been developed for the diagnosis of human echinococcosis. These are generally more reliable for AE than for CE. Such tests can be used to give the clinician additional information when imaging techniques are inconclusive.

\section{Treatment}

There are numerous important reviews on the therapeutic management of CE. However, it still is a controversial subject. Consensus opinion was reached within the WHO-IWGE and the main conclusions published in 1996 (WHO-IWGE, 1996) with updated recommendations published in 2010 (Brunetti et al, 2010). Surgery was the only option until the late 1970s. Complementary or alternative options are now available, which include non-surgical interventional and chemotherapy with anti-parasitic drugs. Treatment indication should be based on a multidisciplinary discussion and depends on cyst type, number and location, and presence or absence of cyst complication. A proper and long-term follow-up of the patients should assess the efficacy of the treatment, detect treatment complications, and timely disclose recurrences. Percutaneous puncture (PAIR) for inoperable cases is currently accepted as an alternative to surgery in selected cases. This includes puncture of the cyst, aspiration of the fluid content of the cyst, introduction of a protoscolicide, such as hypertonic saline or, preferably, alcohol and re- 
aspiration. It is carried out under ultrasonic guidance. Detailed practical guidelines have been published by the WHO-Informal Working Group (WHO-IWGE, 2001)

With AE patients should always be treated with benzimadazoles combined with surgical resection of the parasitic lesion. Based on the WHO-PNM classification of $\mathrm{AE}$ cases and international group of experts has recently suggested various approaches of therapeutic procedures depending on the stage of the disease and on the available resources.

\section{Epidemiology and Transmission to Man}

The highest incidences of $\mathrm{CE}$ are seen where there is a close association with man and domestic livestock, often using working dogs. A common source of infection for dogs is offal from infected sheep. The resultant high infection levels in these dogs then pose a risk to humans. The cohabitation with dogs and feeding of uncooked viscera is a known risk factor for human CE.

The potential for domestic transmission of E. granulosus is highest in countries where the level of education may be poor, veterinary and medical services inadequate and where home slaughter is commonly practiced. In such circumstances, prevalences in dogs can reach between 20 and $50 \%$ with perhaps an excess of $50 \%$ of the sheep population being infected. Occasionally other species, such as camels and pigs, may also be intermediate important hosts. Dogs themselves are more likely to become infected if they are young, allowed to roam, fed on raw offal, offal in the community is not disposed of properly, the dogs do not receive anthelmintic treatment or the dogs' owners are ignorant of the disease.

The distribution of CE is global (figure 5), but different parts of the world have markedly different human incidences. In Europe autothochonous CE is generally rare in central and northern Europe, although there are some foci in Eastern Europe which are believed to be mainly through transmission of the pig strain. The most intensely endemic areas are Spain; where in some districts human incidence rates are 1.1-3.4/100,000/year and Italy, particularly Sardinia where annual human incidence rates are 3.5/100,000. CE is also an emerging problem in Greece, Bulgaria and Romania where incidences of 3.3/100,000/year have been recorded. There is also a small focus in Wales in the United Kingdom.

\section{Insert figure 5 about here}

$\mathrm{CE}$ is a significant problem across much of the Middle East and North Africa. In Jordan the annual incidence is $2.9 / 100,000$, in Tunisia $15 / 100,000$ and in Turkey $0.67-6.6 / 100,000$. In central Asia there has been a resurgence of CE following the collapse of the Soviet Union. This was due to poor funding of veterinary public health services, closure of centralised meat processing units and the privatisation of large collectivised livestock enterprises. This enabled increased transmission of E. granulosus between dogs and livestock and from dogs to man. Consequently 
surgical incidence rates are now commonly between 10 and 20/100,000 in much of central Asia. A similar pattern is also emerging in other former communist countries like Bulgaria.

Certain communities in Tibet have some of the highest incidences of CE. In some villages US prevalences range between 5-10\%. Similar disease burdens have also been recorded in transhumant pastoral communities in East Africa, such as the Turkana and Masai in Kenya and Tanzania, Toposa in Sudan and the Dassanetch and Nyangatom in southern Ethiopia.

In Latin America there are large endemic areas throughout the Andean regions of Peru, Argentina, Chile, Uruguay southern Brazil and sporadic cases being reported elsewhere such as Mexico.

In the US and Canada, CE tends to be sporadic and rare with cases occasionally being reported in certain groups of native Americans or particular ethnic groups.

In Australasia $\mathrm{CE}$ was introduced with European colonisation and became a problem in large sheep rearing areas. Successful control programmes have resulted in the elimination of the parasite from New Zealand and Tasmania. In continental Australia the parasite has established a wild life cycle between macropod marsupials and dingoes. Therefore prospects for elimination are now considered bleak. There are often descriptions of transmission within the domestic cycle and human $\mathrm{CE}$ is frequently recorded.

E. multilocularis occurs in the northern hemisphere within a large belt stretching from the Arctic $\left(80^{\circ} \mathrm{N}\right)$ southward to some regions around the $30^{\text {th }}$ degree of northern latitude (figure 6). The currently known endemic zone includes regions in Europe, Asia (extending eastward to Japan) and North America. Over $90 \%$ of human AE cases are in China where there is a heavily endemic region on the Tibetan plateau. In some communities $5 \%$ or more of the population may be infected. Elsewhere there are human cases reported from central and Eastern Europe, Turkey, much of Russia central Asia and Japan.

\section{Insert figure 6 about here}

In western and central Europe, E. multilocularis is typically perpetuated in a wildlife cycle, involving red foxes (Vulpes vulpes) as definitive hosts and rodents (Microtus arvalis, Arvicola terrestris, Myodes [= Clethrionomys] glareolus and other species) as intermediate hosts. Prevalences of E. multilocularis in red foxes range from about $1 \%$ to more than $60 \%$ in various regions. In other regions such as China and central Asia, dogs are also infected as definitive hosts. This may increase the possibilities for transmission to man or contamination of food with parasite eggs. .

Echinococcosis is not always associated with dog ownership or indeed contact with dogs or other carnivores. This may be because in some highly endemic areas dog ownership is universal and therefore cannot be used to discriminate between infected and non infected subjects. Some 
groups such as Muslims regard dogs as unclean and therefore are unlikely to have close contact with them. Despite this CE infection amongst many of these people is evidence for indirect transmission of echinococcosis to man through contaminated food or water supplies. Epidemiological and experimental evidence has demonstrated that parasite eggs can be transmitted considerable distances by mechanical carriers such as insects. Thus, in highly endemic areas it is quite possible for individuals to contract $\mathrm{CE}$ even in the absence of dog contact.

Women are often reported to have a higher incidence of infection then men and this may be because they are more likely to tend to the household dogs and be involved with food preparation. In some populations men are found to have a higher incidence: this may reflect that in some societies men are more likely to be treated because they are more economically active, rather than an actual increased risk for men. Increasing age is also often reported as a risk factor with the peak age being 30-50 years. This is most likely due to continuous infection opportunities over time and the chronic and asymptomatic nature of abdominal CE. (Macpherson et al. 2004).

\section{Foodborne Transmission}

Both cystic and alveolar echinococcosis can be transmitted to man through food. This is through contamination of food with parasite eggs and thus could occur where there is the possibility of contamination of food with dog or fox faeces. Although not a consistent finding, there are studies that indicate an association of human infection with home grown vegetables which, presumably have been contaminated by dog faeces. In addition studies have shown an association with leaving food uncovered and thus available to flies. This is a potentially important means of human infection as flies have been shown to be capable of transmitting parasite eggs after they have fed on dog faeces.

An unsafe water supply (such as from a stream) is also associated with infection with CE or $\mathrm{AE}$ in some studies and this may be due to water contamination with dog faeces. This water can then contaminate food during food preparation

With alveolar echinococcosis there is also a study linking the disease with eating wild fruit. This may be due to wild berries being contaminated with fox faeces. However, a major issue that is difficult to resolve is source attribution for echinococcosis. This is because there is a long time lag, often of a number of years, between infection and the development of clinical signs which makes it extremely difficult to identify the source of infection.

One recent study in Libya identified parasite eggs in vegetables and these could well include Echinococcus eggs. Tomato, cucumber, lettuce and cress samples were examined for parasite eggs and Taenia/Echinococcus eggs were found in 3\%, 8\%, 37\% and 33\% of samples respectively. This therefore provides strong evidence that inadequately washed and prepared salad vegetables are a potential source of infection. 
An important point with regard to public health is animal offal that contains hydatid cysts (eg infected sheep liver). Such infected organs cannot directly infect humans even if consumed raw as the metacestode is NOT infectious to humans but must first infect a dog. Generally offal containing hydatid cysts would be condemned and removed from the food chain. This is for two reasons. First the organ would be regarded as unwholesome and hence not suitable for human consumption. More importantly the organ could be infectious to dogs and thus must be destroyed to prevent dogs becoming infected. A dog infected with Echinococcus is a substantial health hazard to its owner or indeed anyone coming in contact with this dog.

\section{Economics and Societal Burden}

CE presents a considerable societal and economic burden to a number of societies where $E$. granulosus is endemic. In terms of animal health the disease can lead to significant losses of production due to liver condemnations, lowered milk, meat and wool production or decreased fertility in animals. This particularly impacts on societies with low socio economic development which have the highest prevalences in livestock.

A number of studies have estimated the economic costs of $\mathrm{CE}$ in various countries and it is often considerable. There is also a financial estimate of the global costs of CE which suggests it could be as much as $\$ 3$ billion annually if estimates for underreporting of the disease are accounted for.

A preliminary estimate of the global burden on echinococcosis has also been made which indicates a loss of approximately 1 million DALYs. This is of a similar magnitude to the global burden of Trypanosomiosis or Schistosomiosis and considerably more than diseases such as Dengue or Leprosy. Similarly the global burden of AE has been estimated to be approximately 600,000 DALYs with approximately 18,000 new cases annually.

Burden estimates present important methods in developing cost effective means of controlling this often neglected zoonosis. These estimates confirm that both $\mathrm{CE}$ and $\mathrm{AE}$ are major health problems in many parts of the world. However, what is less certain is the proportion of echinococcosis that is transmitted to man through the consumption of unsafe food that has been contaminated with Echinococcus eggs.

\section{Prevention and Control}

Control of CE has always involved a combination of routine anthelmintic treatment of dogs, control and reduction of stray dog populations, supervision of the slaughter of livestock and subsequent disposal of offal, and education of the public. A sheep vaccine has also recently been developed. This will prevent sheep becoming infected and hence break the cycle. Since this would then remove the source of infection for dogs, transmission to humans will be reduced or cases. The various options for controlling CE are reviewed in Torgerson et al. (2011). By 
implementing a carefully planned control strategy it is possible to eliminate E. granulosus and this has occurred in some Island nations such as New Zealand.

There is concern in Europe that fox populations are increasing and foxes are being found in greater numbers in the urban environment. This has lead to an increase in the numbers of human $\mathrm{AE}$ cases in countries such as Switzerland. Control of $\mathrm{AE}$ is more problematic then $\mathrm{CE}$ as $E$. multilocularis has a wild life cycle. However there has been some success by the distribution of praziquantel impregnated baits to foxes. In China it is possible that dogs play an important role in the transmission of $\mathrm{AE}$. Thus periodic treatment of dogs with praziquantel may ameliorate transmission.

\section{Conclusions}

Echinococcosis can be a food borne disease but the extent that is foodborne is difficult to quantify. To prevent food becoming contaimnated with Echinococcus eggs, dogs and other carnivores must be totally excluded from any food preparation or storage areas. They should also be frequently treated with praziquantel. Dog faeces should be properly disposed of and never used as a fertilizer for crops. Adequate cleaning and cooking of food should also minimize the risk of foodborne echinococcosis. Finally food should not be accessible to flies as flies can carry Echinococcus eggs and thus act as a conduit of eggs from canine faeces to food.

\section{Further reading}

Abougrain, N.. K., Nahaisi, M. H., Madji, N. S., Saied, M. M. \& Ghenghesh, K. S. (2010). Parasitologfical contamination in salad vegetables in Tripoli-Libya. Food Control 21, 760-762

Budke, C. M., Deplazes, P. \& Torgerson, P. R. (2006). Global socioeconomic impact of cystic echinococcosis. Emerging Infectious Diseases 12, 296-303.

Brunetti, E., Kern, P., Vuitton, D.A.; Writing Panel for the WHO-IWGE. (2010). Expert consensus for the diagnosis and treatment of cystic and alveolar echinococcosis in humans. Acta Tropica 114, 1-16

Carmena, D., Benito, A. \& Eraso, E. (2006). Antigens for the immunodiagnosis of Echinococcus granulosus infection: an update. Acta Tropica, 98, 74-86.

Carmena, D., Benito, A., and Eraso, E. (2007). The immunodiagnosis of Echinococcus multilocularis infection. Clinical Microbiology and Infection 13, 460-475.

Craig, P. S. \& Larrieu, E. (2006). Control of cystic echinococcosis/hydatidosis: 18632002. Advances in Parasitology 61, 443-508. 
Gemmell, M. A. (1990). Australasian contributions to an understanding of the epidemiology and control of hydatid disease caused by Echinococcus granulosus-past, present and future International Journal for Parasitology 20, 431-456.

Kern, P., Ammann, A., Kron, M., et al. (2004). Risk factors for Alveolar Echinococcosis in Humans. Emerging Infectious Diseases 10, 2088-2093.

Kern, P., Wen, H., Sato, N., Vuitton, D. A., Gruener, B., Shao, Y. M., Delabrousse, E., Kratzer, W. \& Bresson-Hadni, S. (2006). WHO classification of alveolar echinococcosis: Principles and application. Parasitology International 55, S283S287.

Lawson, R. and Gemmell, M. A. (1990) Transmission of taeniid tapeworm eggs via blowflies to intermedaite hosts. Parasitology 100, 143-146

Schweiger, A., Ammann, R.W., Candinas, D., Clavien, P.A., Eckert, J., Gottstein, B., Halkic, N., Muellhaupt, B., Prinz, B.M., Reichen, J., Tarr, P.E., Torgerson P.R., and Deplazes, P. (2007). Human alveolar echinococcosis after fox population increase, Switzerland. Emerging Infectious Diseases 13, 878-882.

Torgerson, P. R. (2003). Economic effects of echinococcosis. Acta Tropica 85, 113118.

Torgerson, P. R., Keller, K., Magnotta, M. and Ragland, N. (2010) The Global Burden of Alveolar Echinococcosis Plos Neglected Tropical Diseases, 4(6), e722

Torgerson, P. R., Vuitton, D. and MacPherson, C. (2011). Cystic echinococcosis. In Palmer, S., Soulsby, Lord, Torgerson, P. R. and Brown, D.(eds) Zoonoses $2^{\text {nd }}$ edition, Oxford University Press

Wang, Q., Qui, J., Yang, W., et al. (2006). Socioeconomic and behavior risk factors of human alveolar echinococcosis in Tibetan communities in Sichuan, People's Republic of China. American Journal of Tropical Medicine \& Hygiene 74, 856-862. WHO/OIE (2001). Manual on Echinococcosis in Humans and Animals: a Public Health Problem of Global Concern (ed. J. Eckert, M.A. Gemmell, F.-X. Meslin, Z.S. Pawlowski). World Organisation of Animal Health, Paris. ISBN 92-9044-522X. 


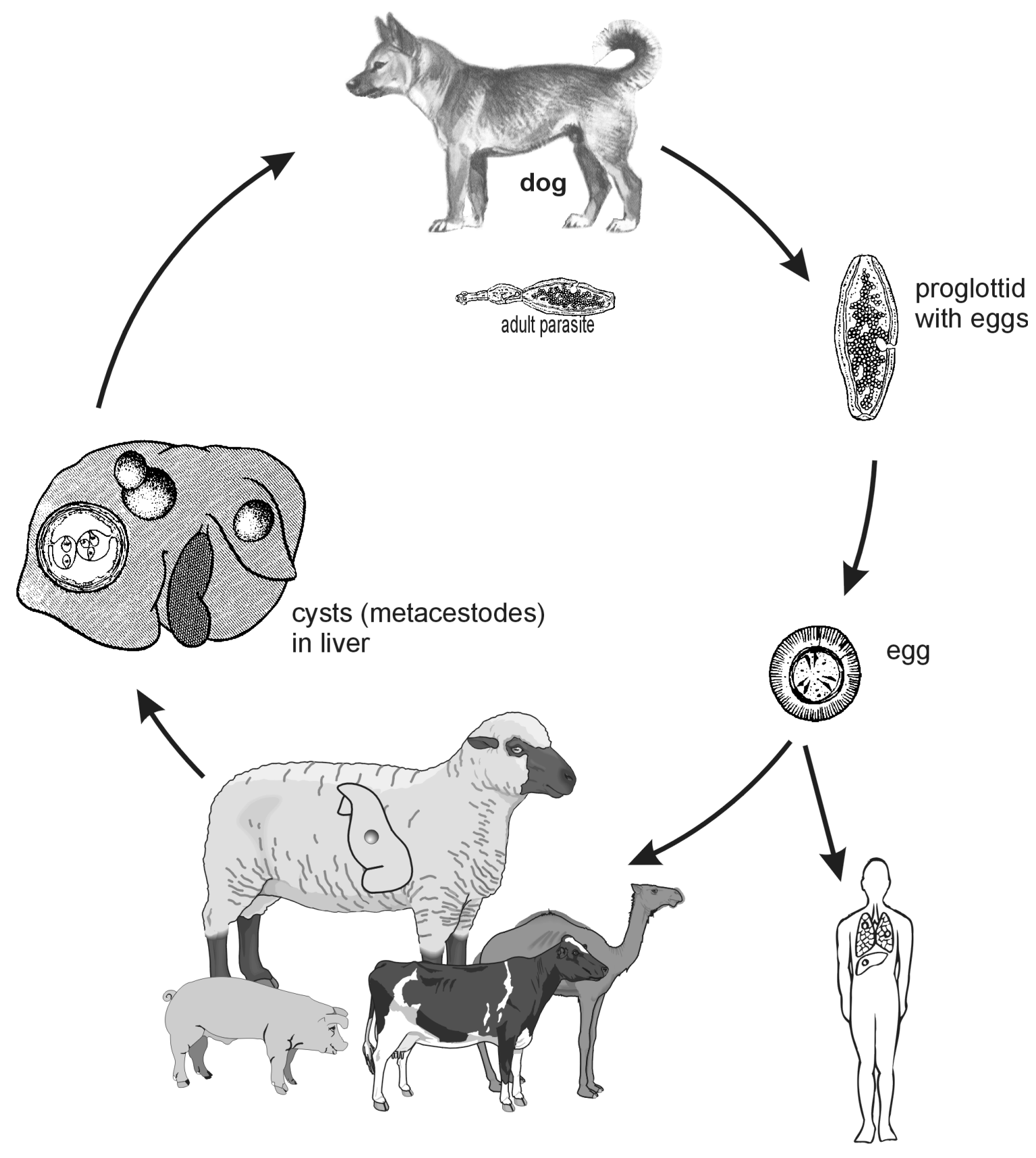

(C) Institute of Parasitology, University of Zurich

Figure 1: Life cycle of Echinococcus granulosus complex of genotypes frequently encountered in man. E. granulosus sensu stricto commonly utilizes sheep as the intermediate host. E. ortleppi, E. intermedius and E. canadensis are often associated with cattle, pigs or camels, or wild ungulates respectively. 
Table 1. Aetiology of cystic and alveolar echinococcosis in humans

\begin{tabular}{|c|c|c|c|}
\hline Echinococcus species & $\begin{array}{l}\text { Name, (abbreviation ) and } \\
\text { synonym of disease }\end{array}$ & $\begin{array}{l}\text { Common } \\
\text { Intermediate Hosts }\end{array}$ & Geographical distribution \\
\hline $\begin{array}{l}\text { Echinococcus } \\
\text { (sensu stricto) }\end{array}$ & Cystic Echinococcosis (CE) & Sheep & Global \\
\hline Echinococcus ortleppi* & Cystic echinococcosis & Cattle & $\begin{array}{l}\text { Europe, South Africa, India, } \\
\text { Russia, possibly south } \\
\text { America }\end{array}$ \\
\hline Echinococcus intermedius* & Cystic echinococcosis & $\begin{array}{l}\text { Pigs, camels, } \\
\text { possibly goats }\end{array}$ & $\begin{array}{l}\text { Middle East, central Asia, } \\
\text { China, India, Africa, } \\
\text { eastern Europe, Argentina }\end{array}$ \\
\hline Echinococcus canadensis* & Cystic echinococcosis & $\begin{array}{l}\text { Wild ungulates } \\
\text { such as deer }\end{array}$ & $\begin{array}{l}\text { Northern Eurasia and } \\
\text { North America }\end{array}$ \\
\hline Echinococcus multilocularis & Alveolar echinococcosis (AE) & Small mammals & $\begin{array}{l}\text { Northern hemisphere } \\
\text { (Eurasia, North America) }\end{array}$ \\
\hline
\end{tabular}

*Previously classified as Echinococcus granulosus. Further possible species exists - E. equinus and $E$. felidis. The former is not thought to be infectious to man whilst the latter's infectivity to man is unknown 


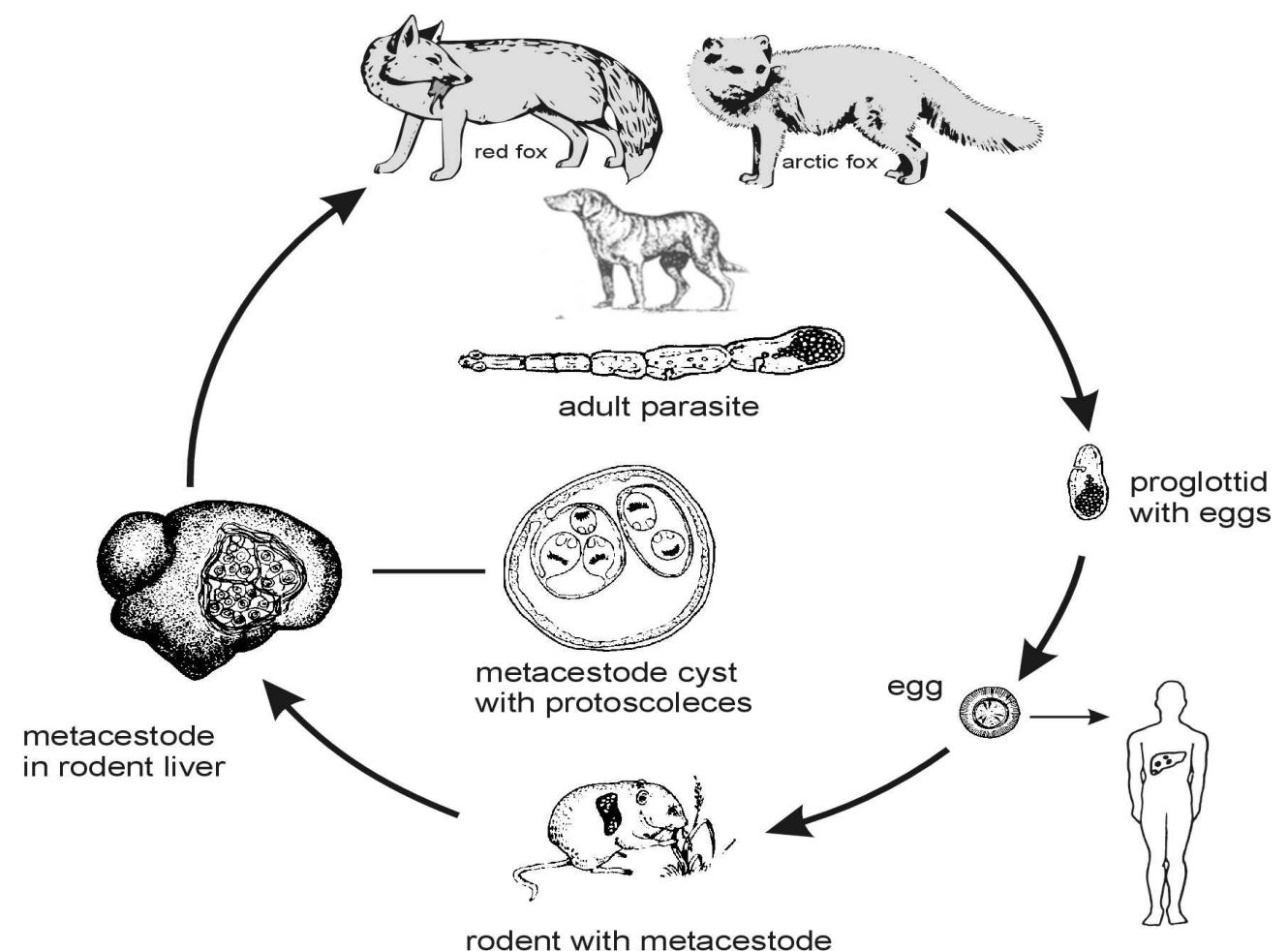

Figure 2. Life cycle of Echinococcus multilocularis. Man is an aberrant intermediate host and is infected directly or indirectly (for example via contaminated food) from fox or dog faeces. (C) Institute für Parasitologie, Universität Zürich 


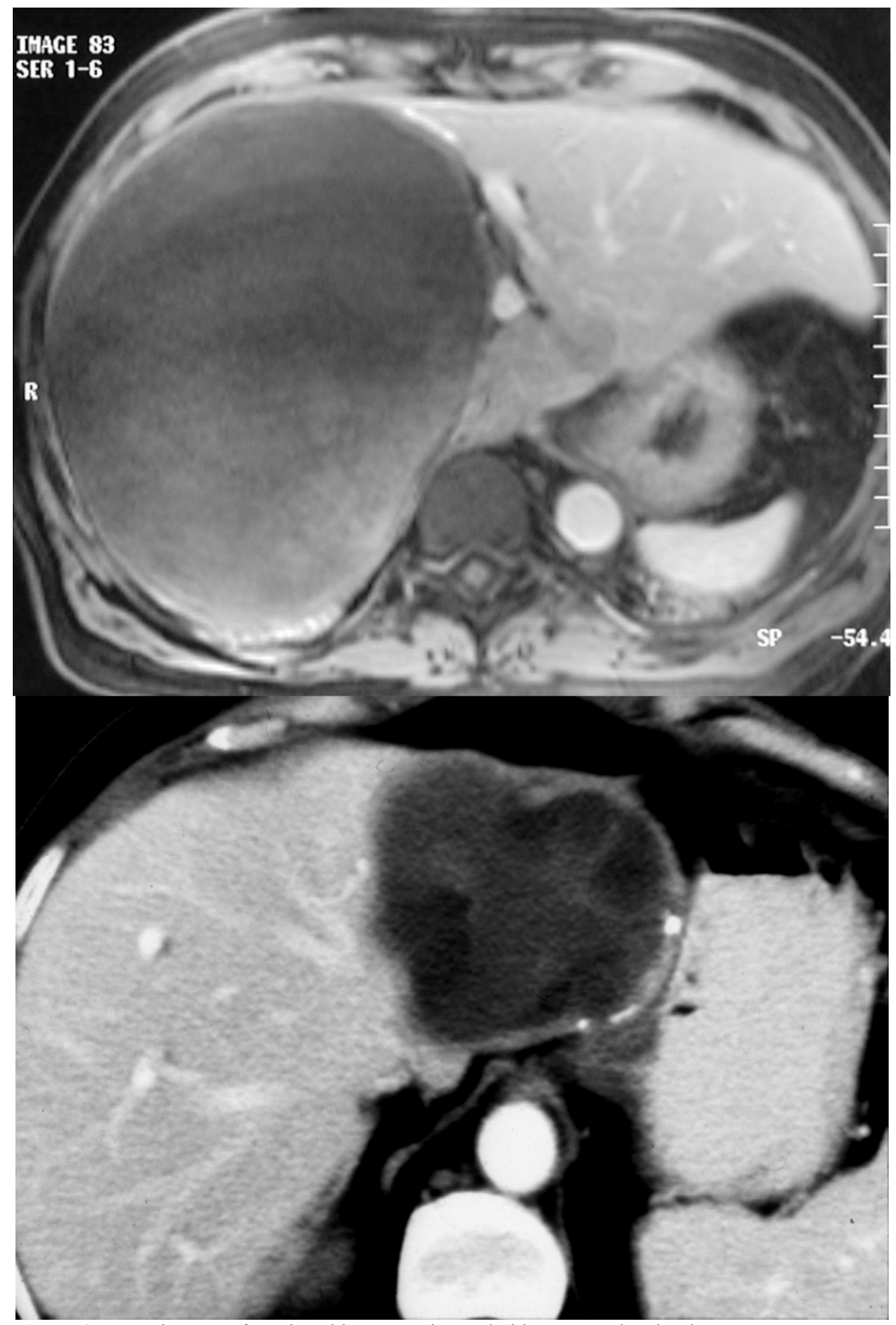

Figure 3. NMR images of cystic echinococcosis. Hydatid cysts can be clearly seen as space occupying lesions in the liver. Images from (Aliev et al. 2004) with permission. 


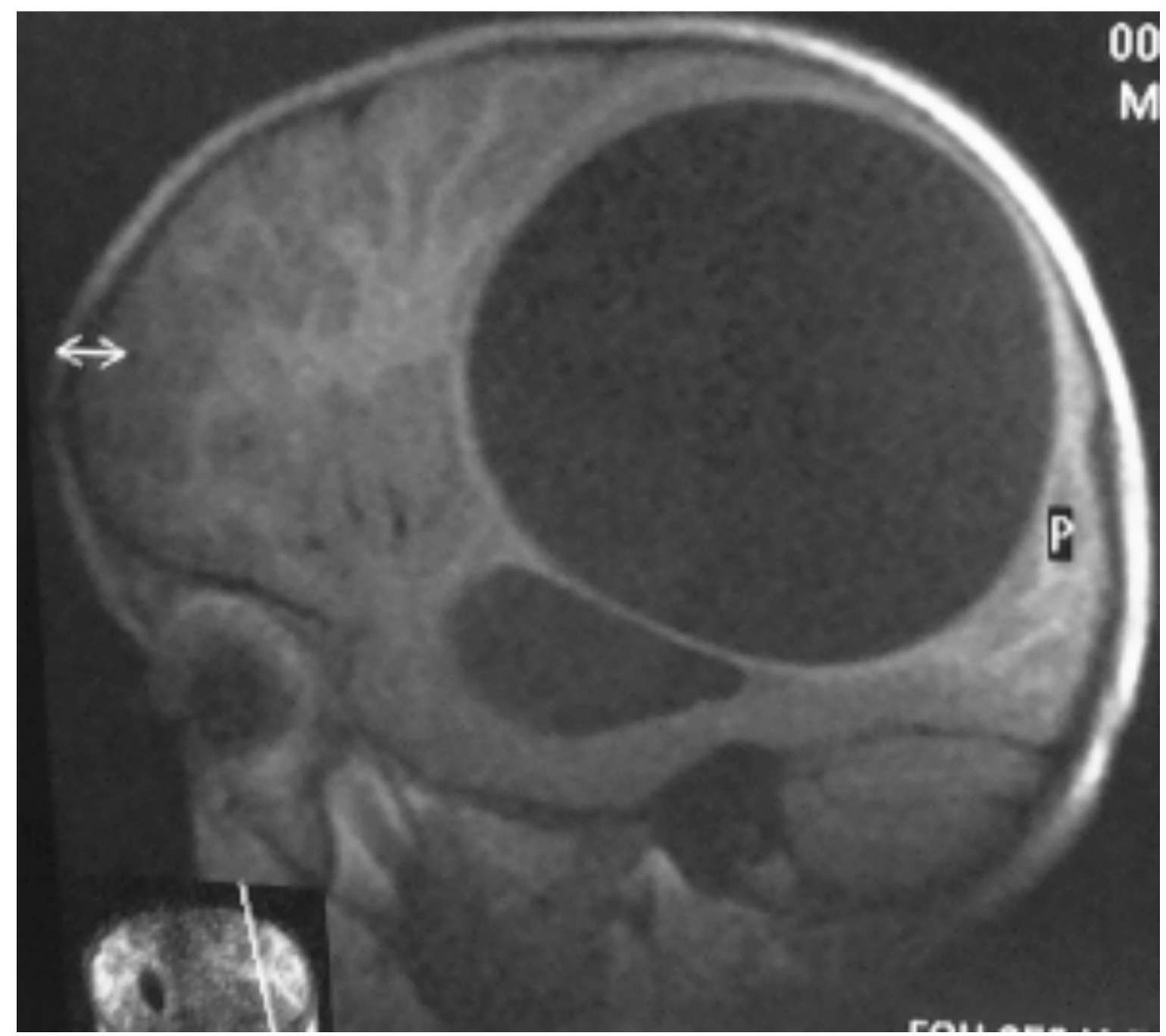

Figure 4. CAT scan of cerebral echinococcosis.

Although CNS involvement of echinococcosis is rare, when it does occur it can be a devastating condition. Image supplied by the Government Pediatric Hospital, Bishkek, Kyrgyzstan 


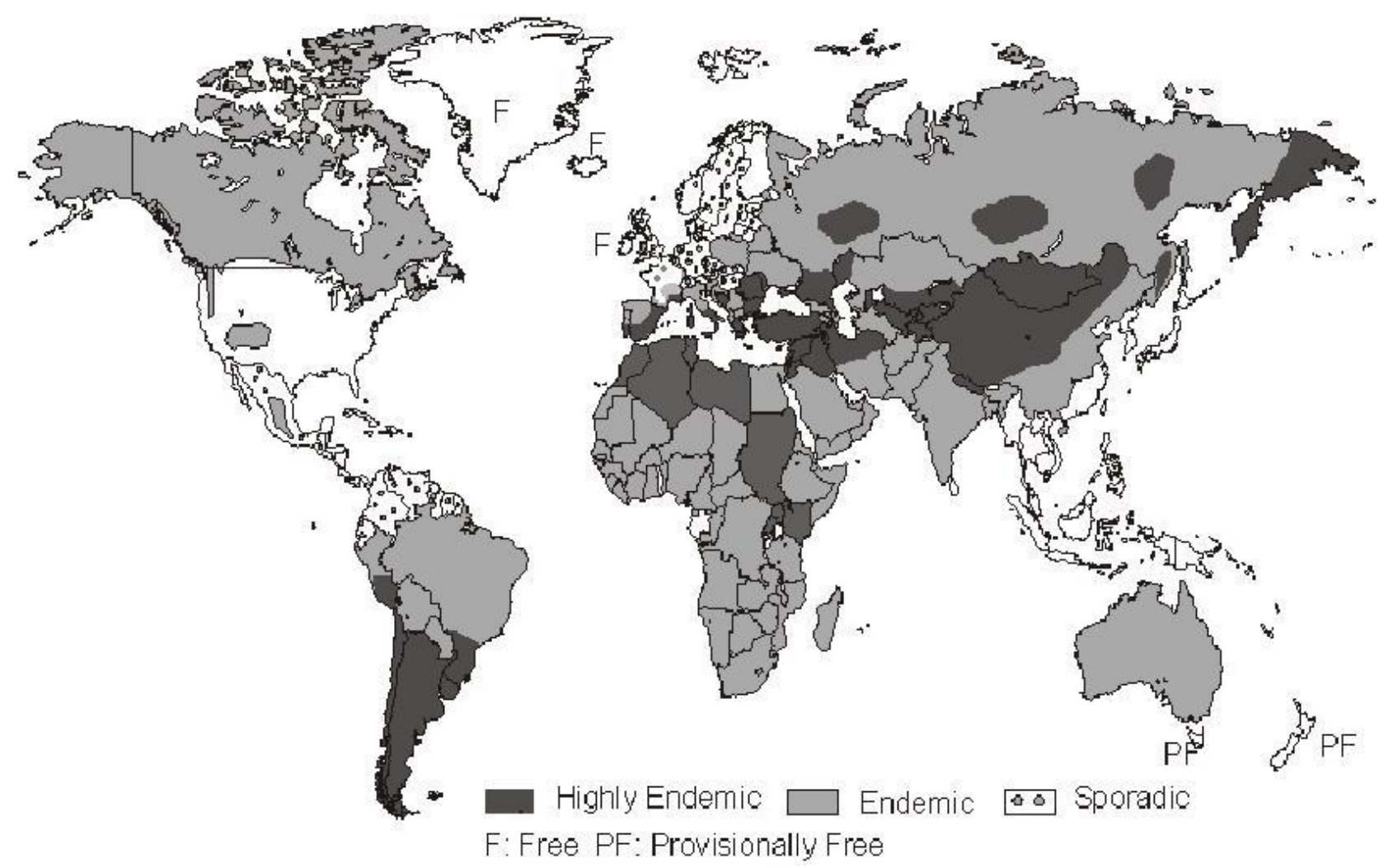

Figure 5. Approximate geographical distribution of the zoonotic strains of E. granulosus. Adapted from Eckert et al, (2000, 2001). (C) Institute für Parasitologie, Universität Zürich. Ireland is free of zoonotic Echinococcus spp, but is endemic for E. equinus 


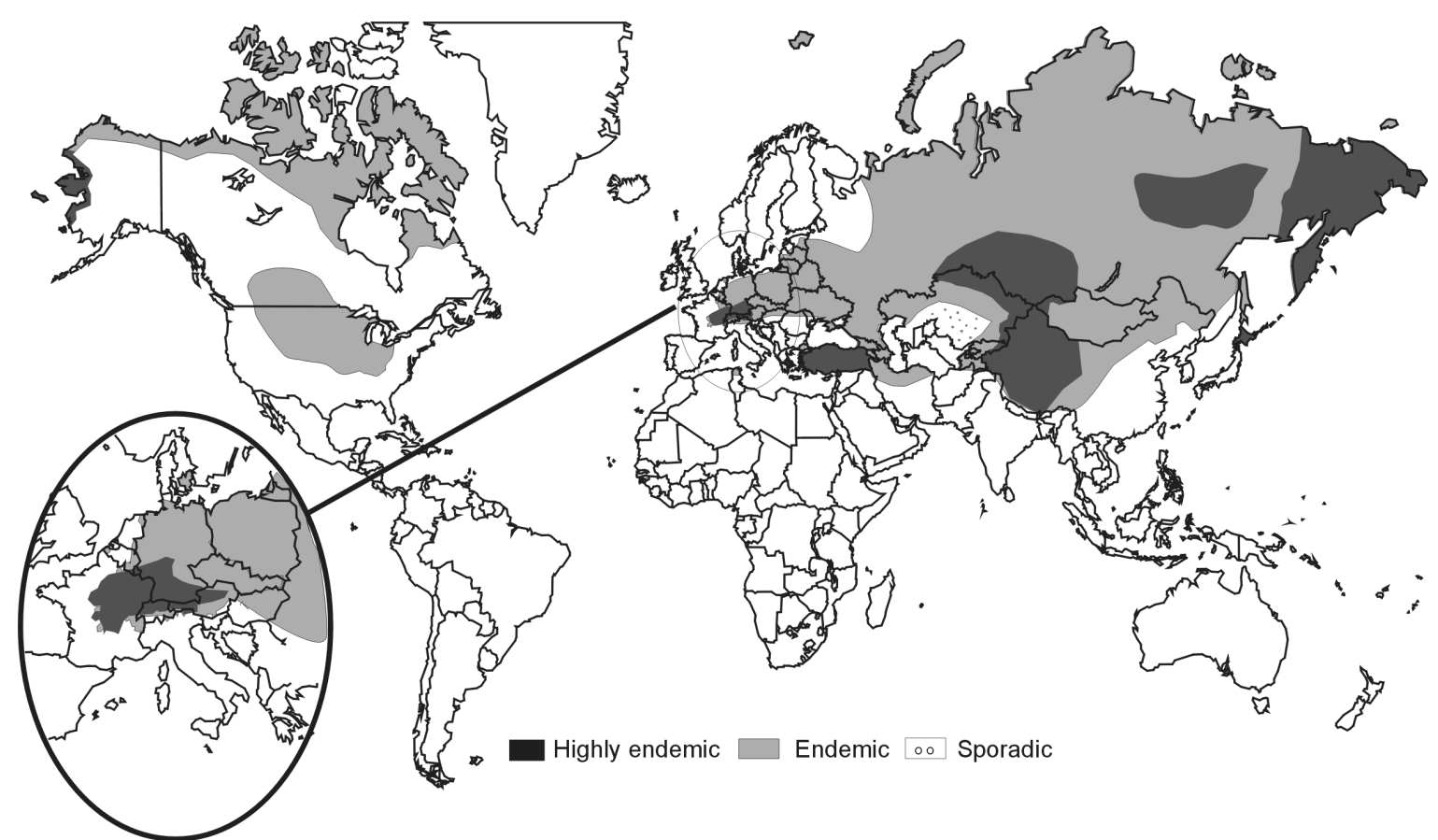

Figure 6. Global distribution of Echinococcus multilocularis Image supplied by the Institute of Parasitology, Zurich 